\title{
Safety and efficacy of ferric carboxymaltose in anaemic antenatal women: a prospective study
}

\author{
Supriya Jamkhandi, Rajesh Tile*
}

Department of Obstetrics and Gynecology, ESIC Medical College, Kalaburgi, Karnataka, India

Received: 28 January 2021

Accepted: 04 April 2021

\section{*Correspondence:}

Dr. Rajesh Tile,

E-mail: sjsupriyajamkhandi@gmail.com

Copyright: ( ) the author(s), publisher and licensee Medip Academy. This is an open-access article distributed under the terms of the Creative Commons Attribution Non-Commercial License, which permits unrestricted non-commercial use, distribution, and reproduction in any medium, provided the original work is properly cited.

\begin{abstract}
Background: Anemia is one of the most common nutritional deficiency disorders affecting the pregnant women, and is a worldwide problem. In India, prevalence ranges from $23.6 \%-61.4 \%$ and contributes to $80 \%$ of maternal mortality as a direct or indirect cause. This study aims to assess the efficacy and safety of intravenous ferric carboxymaltose in antenatal women with moderate anemia in the second and third trimester of pregnancy.

Methods: Prospective clinical study; total of 100 antenatal women with moderate anemia in second and third trimester were included in the study from January 2019 to September 2019 and given 1000mg of intravenous ferric carboxymaltose injection. Efficacy was assessed by rate of improvement in hemoglobin at 3 and 6 weeks post infusion. Safety analysis was done by assessing the adverse drug reactions and fetal heart monitoring during the infusion.

Results: A total 100 antenatal women with median gestational age of 28 week at presentation received $1000 \mathrm{mg}$ of intravenous ferric carboxymaltose. There was rise in hemoglobin from $8.3 \mathrm{gm} \%$ before injection to $11.12 \mathrm{gm} \% 6$ weeks post infusion, showing a mean rise of $2.8 \mathrm{gm} \%$. There were no reports of drug related major adverse effects in the mother or the fetus.

Conclusions: From this study, ferric carboxymaltose is found to be safe and effective treatment option for anemia in pregnancy.
\end{abstract}

Keywords: Anemia, Antenatal, Ferric carboxymaltose, Parenteral iron

\section{INTRODUCTION}

Anaemia is a common problem in obstetrics and perinatal care and is of global concern. According to WHO 2011 report about 32.4 million pregnant women suffer from anaemia worldwide, of which more than $50 \%$ cases are attributed to iron deficiency. ${ }^{1}$

India has the utmost prevalence of iron deficiency anaemia i.e. 57-96.2\% among the South Asian countries and also has highest contribution of $80 \%$ towards maternal death both as direct and indirect cause among this region. Anaemia in pregnancy is defined as haemoglobin $(\mathrm{Hb})$ levels $<11 \mathrm{gm} \%$ and hematocrit $<33 \%$ as per $\mathrm{WHO}^{2}$ According to $\mathrm{CDC}$, definition in pregnancy is $\mathrm{Hb}$ level $<10.5 \mathrm{gm} \%$ in the I and III trimesters and $\mathrm{Hb}$ $<11$ gm $\%$ during II trimester. ${ }^{3}$ It is classified depending upon the $\mathrm{Hb}$ levels into mild ( $\mathrm{Hb}-10-10.9 \mathrm{gm} \%$ ), moderate ( $\mathrm{Hb} 7-9.9 \mathrm{gm} \%)$, severe $(\mathrm{Hb}-4-6.9 \mathrm{gm} \%)$ and very severe $(\mathrm{Hb}-<4 \mathrm{gm} \%)$ according to the ICMR. ${ }^{4}$

In addition to the general consequences of anaemia, there are specific risks during pregnancy like susceptibility towards infections, risk of postpartum hemorrhage, increased need for blood transfusion and longer hospital stay. ${ }^{5,6}$

Maternal anemia is also associated with higher perinatal morbidity, mortality and higher infant mortality rate. ${ }^{7}$ Early detection and effective management of anemia in 
pregnancy, thus reduces significant maternal and perinatal morbidity and mortality.

Therapy for iron deficiency includes dietary modification, oral iron supplementation, parenteral iron and blood transfusion. Oral iron is often used as prophylaxis and is also the recommended first line treatment of iron deficiency anaemia in pregnancy.

However the major drawback of oral iron is gastrointestinal adverse effects, unpredictable absorption rates, reduced compliance, long course of therapy and is also ineffective in the treatment of severe cases of anemia. $^{8,9}$ Therefore parenteral iron is an effective alternative treatment option in cases with moderate to severe anaemia, in case of intolerability to oral iron and/or if there is a need for rapid restoration of iron stores.

Iron sucrose is the most commonly used intravenous preparation with good safety profile in pregnancy. ${ }^{10}$ The main drawback being risk of toxicity with higher doses of administration thus requiring multiple hospital visits, putting a heavy burden on the hospital resources as well as for the patient. Intravenous Ferric Carboxymaltose is a novel iron complex which consists of a ferric hydroxide core stabilized by a carbohydrate shell.

The advantage of administering large doses $(15 \mathrm{mg} / \mathrm{kg}$; maximum of $1000 \mathrm{mg} / \mathrm{infusion}$ ) in a single and rapid session (15 minute infusion) are due to its properties of near neutral $\mathrm{pH}$, physiological osmolarity and increased bioavailability.

Moreover, the risk of anaphylaxis or serious hypersensitivity reactions is very low with FCM, and a test dose is also not required. The safety and efficacy of FCM has been evaluated and proven in the postpartum period by various studies in the literature. ${ }^{11-14}$ However few studies are available on the use of FCM in the antenatal period. ${ }^{15-18}$

In this study we assess the safety and efficacy of intravenous ferric carboxymaltose in the treatment of anemia in the second and third trimesters.

\section{METHODS}

\section{Study design}

Prospective clinical study

\section{Study setting}

Department of Obstetrics and Gynaecology, ESIC Medical College and Hospital, Kalaburgi. The study was approved by the Medical Ethics Committee of the Institution. Total of 100 antenatal women attending the OPD from January 2019 to September 2019 were included in the study.

\section{Inclusion criteria}

All the pregnant women attending antenatal OPD between II trimester to III trimester with hemoglobin $\leq 9 \mathrm{gm} / \mathrm{dl}$. Demonstrated the ability to understand the requirements of the study and provide written informed consent for their participation in the study.

\section{Exclusion criteria}

Anemic pregnant women with hypertensive disorders in pregnanc, anemia due to megaloblastic anemia, thalassemia, sickle cell anemia, aplastic anemia, serious medical condition or any uncontrolled systemic disease e.g. chronic renal disease, severe cardiovascular disease, chronic or acute hepatic disorder, tuberculosis etc and known hypersensitivity to FCM or other IV iron preparations.

Subjects received an infusion of $1,000 \mathrm{mg}$ FCM diluted in $200 \mathrm{ml}$ of $0.9 \% \mathrm{NaCl}$ and given over a period of $30 \mathrm{mins}$. During the infusion the mother was monitored for signs and symptoms of anaphylaxis and pulse rate and blood pressure checked every $15 \mathrm{mins}$. Fetal heart rate was assessed before and after the infusion and $15 \mathrm{mins}$ midway through the infusion. The women were kept under observation in the hospital for at least 4 hours for signs of any intolerance. All minor and major local and systemic side effects were documented. Blood samples were collected to measure hemogram before the infusion and repeated 3 and 6 weeks post infusion.

\section{Outcome measures}

Demographic characteristics and baseline data included maternal age, gestational age and results from peripheral blood counts. Outcome data were collected on improvement in $\mathrm{Hb}$ levels 6weeks post infusion and maternal and fetal adverse events. Adverse events (AEs) were defined as allergic or hypersensitivity reactions during or after the infusion of FCM.

\section{Statistical analysis}

Statistical analysis was performed using IBM SPSS Statistics. For statistical comparison, ANOVA tests were used, where appropriate $p$ values $<0.05$ were considered statistically significant.

\section{RESULTS}

Total of 100 antenatal women received intravenous infusion of ferric carboxymaltose injection $1000 \mathrm{mg}$ for iron deficiency anemia. The demographic characteristics are outlined in Table 1 . The mean gestational age of the study population was 28 weeks. Majority of the women with IDA were in the age group of 26-30yrs as shown in the Table 2 and the urban population were showing higher prevalence of anemia as shown in Table 3. 
Table 1: Demographic features.

\begin{tabular}{|ll|}
\hline Characteristics & Mean values \\
\hline Age (years) & 24.3 \\
\hline Parity & 1 \\
\hline Gravida & 2.6 \\
\hline Gestational age(weeks) & 28 \\
\hline
\end{tabular}

Table 2: Distribution according to age.

\begin{tabular}{|ll|}
\hline Age (in years) & No. of women \\
\hline $\mathbf{2 0}$ & 11 \\
\hline $\mathbf{2 1 - 2 5}$ & 33 \\
\hline $\mathbf{2 6 - 3 0}$ & 37 \\
\hline $\mathbf{3 1 - 3 5}$ & 19 \\
\hline
\end{tabular}

Table 3: Distribution according to habitat.

\begin{tabular}{|ll|}
\hline Habitat & No. of women \\
\hline Rural & 43 \\
\hline Urban & 57 \\
\hline
\end{tabular}

As shown in the Table 4, the prevalence of anaemia was higher in the multigravidas in comparision to the primigravidas in our study, this can be attributed to increasing number of pregnancies, lack of spacing, ignorance and self-negligence.

Table 4: Prevalence of anaemia depending upon parity.

\begin{tabular}{|ll|}
\hline Parity & No. of women \\
\hline Primigravida & 29 \\
\hline Multigravida & 71 \\
\hline
\end{tabular}

All women received single dose of $1000 \mathrm{mg}$ ferric carboxymaltose except for 5 out of 100 patients who required 2 doses of $1000 \mathrm{mg}$ of FCM, due to persistent anemia and lower values of $\mathrm{Hb}$ at the time of administration of first dose (median $\mathrm{Hb}-7.1 \mathrm{gm} / \mathrm{dl}$ ).

The hemoglobin values were repeated at 3 weeks and 6 weeks post infusion and the data were collected. All women reported improvement in the hemoglobin after infusion. The changes in the hemoglobin concentrations are presented in the Table 6 . The preinfusion hemoglobin values were significantly lower as compared to the 6 weeks post infusion values; there was a mean rise of $2.8 \mathrm{gm} / \mathrm{dl}$.

Table 6: Changes in hematological parameters.

\begin{tabular}{|lllll|}
\hline \multirow{2}{*}{ Parameters } & \multicolumn{3}{l}{ Change in parameters } & P \\
\cline { 2 - 5 } & Initial & 3 weeks & 6 weeks & value \\
\hline Hemoglobin & 8.3 & 10.4 & 11.1 & 0.000 \\
\hline Hematocrit & 24.9 & 30.7 & 33.4 & 0.007 \\
\hline PCV & 76.5 & 81.2 & 86 & 0.000 \\
\hline
\end{tabular}

In our study, 6 out of 100 patients required blood transfusion after the delivery, of the 6 patients 2 received blood transfusion for atonic PPH and 4 patients for persistent anaemia.

None of the women had major anaphylactic reactions as per Table , minor side effects like utricaria was seen in 4 patients and breathlessness was observed in 5 patients as shown in Table. Concerning the breathlessness, it was transient in nature did not require any intervention and resolved spontaneously. None of the patients reported swelling at injection site and hypotension.

All the women had reactive NST done halfway through infusion and repeated after the infusion, indicating no evidence of fetal distress due to FCM injection.

Table 7: Adverse outcomes.

\begin{tabular}{|ll|}
\hline Adverse reactions & Number \\
\hline Local swelling & 0 \\
\hline Utricaria & 4 \\
\hline Hypotension & 0 \\
\hline Dyspnoea & 5 \\
\hline Fetal distress & 0 \\
\hline
\end{tabular}

\section{DISCUSSION}

Anaemia in pregnancy is associated with significant adverse outcome in both mother and the fetus and is a major cause of maternal and perinatal mortality and morbidity.

The Govt. of India has launched and started various programs and schemes to combat anemia. However it continues to pose a major health challenge despite the persistent and prolonged efforts. The estimated maternal deaths due to IDA is approximately 3,26,000 with an associated disability-adjusted life years (DALYs) of $12,497,000 .{ }^{19}$ The prevalence is higher in urban areas (23.6-61.7\%) as compared to rural areas (19.6-58.1\%). ${ }^{20}$ According to surveys conducted by NFHS 2 and 3 , NNMB and ICMR over $70 \%$ of preschool children, pregnant women and adolescent girls are anemic. ${ }^{21-24}$

Iron sucrose has been the standard of care for parenteral iron therapy for treatment of anemia in pregnancy. However, the main disadvantage of iron sucrose is the need for multiple visits to deliver the required iron dose, while FCM can be administered in a larger amount at a time. Our study investigated the efficacy and safety of FCM during pregnancy. The results of the study showed significant rise of hemoglobin 6weeks after the treatment. Most women received single dose of FCM, only a minority required repeat dose due to persistent anemia. This feasibility of single dose administration is due to high stability of the FCM macromolecule complex and a long half life compared to less stable i.v iron compounds such as ferric gluconate and iron sucrose that requires 
multiple doses. There were no reports of major anaphylactic reactions, or adverse fetal events. Minor side effects were seen in $9 \%$ of the women in the study; these were transient, needed no intervention and resolved spontaneously.
The results of our study are in line with the number of other studies which have shown safe and efficient use of ferric carboxymaltose in pregnancy as shown in Table 8 and Table 9.

Table 8: Results of studies showing Efficacy of FCM injection.

\begin{tabular}{|lllllll|}
\hline Name of study & Study design & $\begin{array}{l}\text { Study } \\
\text { population }\end{array}$ & $\begin{array}{l}\text { Follow up } \\
\text { period }\end{array}$ & $\begin{array}{l}\text { Maximum dose } \\
\text { of FCM }\end{array}$ & $\begin{array}{l}\text { Improvement } \\
\text { in Hb }\end{array}$ & P value \\
\hline $\begin{array}{l}\text { Mahajan et al, } \\
\mathbf{2 0 1 8}^{\mathbf{2 5}}\end{array}$ & Prospective & Antenatal, 50 & 4 weeks & $1000 \mathrm{mg}$ & $3.49 \mathrm{~g} / \mathrm{dl}$ & $<0.001$ \\
\hline $\begin{array}{l}\text { Agarwal D et al, } \\
\mathbf{2 0 1 9}^{\mathbf{2 6}}\end{array}$ & Prospective & Antenatal, 100 & 3 weeks & $1000 \mathrm{mg}$ & $2.92 \mathrm{~g} / \mathrm{dl}$ & $<0.05$ \\
\hline $\begin{array}{l}\text { Froessler et al, } \\
\mathbf{2 0 1 4}\end{array}$ & Prospective & $\begin{array}{l}\text { Antenatal, } 65 \\
\text { women }\end{array}$ & 6 weeks & $1000 \mathrm{mg}$ & $12 \mathrm{~g} / \mathrm{dl}$ & $<0.001$ \\
\hline Joshi SG et al 2016 & Prospective & $\begin{array}{l}\text { Postpartum, } \\
\text { 100 women }\end{array}$ & 6 weeks & $1000 \mathrm{mg}$ & $4.4 \mathrm{~g} / \mathrm{dl}$ & $<0.001$ \\
\hline Jose et al, 201927 & $\begin{array}{l}\text { Randomized } \\
\text { clinical trial }\end{array}$ & $\begin{array}{l}\text { Antenatal, 50 } \\
\text { women }\end{array}$ & 6 weeks & $1000 \mathrm{mg}$ & $2.9 \mathrm{~g} / \mathrm{dl}$ & $<0.001$ \\
\hline $\begin{array}{l}\text { Froessler et al, } \\
\text { 2014 }\end{array}$ & Prospective & Antenatal, 65 & 6 weeks & $1000 \mathrm{mg}$ & $12 \mathrm{~g} / \mathrm{dl}$ & $<0.001$ \\
\hline Christoph et al & Retrospective & Antenatal, 206 & 4 weeks & $1000 \mathrm{mg}$ & $1.5 \mathrm{~g} / \mathrm{dl}$ & 0.08 \\
\hline Present study & Prospective & Antenatal, 100 & 6 weeks & $1000 \mathrm{mg}$ & $2.8 \mathrm{~g} / \mathrm{dl}$ & 0.00 \\
\hline
\end{tabular}

Table 9: Comparison of safety profile of ferric carboxymaltose.

\begin{tabular}{|lllll|}
\hline Name of study & Study design & \multicolumn{2}{l|}{ Side effects } & Fetal \\
\cline { 2 - 4 } & & Maternal & Serious & \\
\hline Mahajan et al, 2018 & Prospective, 50 antenatal women & $30 \%$ & Nil & Nil \\
\hline Agarwal D et al, 2019 & Prospective, 100 antenatal women & Nil & Nil & Nil \\
\hline Christopher et al, & Retrospective, 206 antenatal & $7.8 \%$ & Nil & Nil \\
\hline Froessler et al, 2014 & Prospective, 65 antenatal women & $13 \%$ & Nil & Nil \\
\hline Present study & Prospective, antenatal 100 women & $9 \%$ & Nil & Nil \\
\hline
\end{tabular}

\section{CONCLUSION}

Ferric carboxymaltose has the advantage of single high dose infusion, lesser number of required doses, early rise in $\mathrm{Hb}$ levels and hence fewer clinical visits, better patient compliance and savings in true hospital cost and total productivity loss. Our study shows better safety profile of FCM for both mother and the fetus with fewer minor side effects and no evidence of major anaphylactic reactions or fetal distress.

Thus FCM provides a safe and efficient alternative as a first line therapy for treatment of IDA in pregnancy and hence reducing the disease burden in our country.

\section{Funding: No funding sources}

Conflict of interest: None declared

Ethical approval: The study was approved by the Institutional Ethics Committee

\section{REFERENCES}

1. WHO. The Global Prevalence of Anaemia in 2011. Geneva: World Health Organization; 2015.

2. Ezzati M, Lopus AD, Dogers A, Vander HS, Murray C. Selected major risk factors and global and regional burden of disease. Lancet. 2002;360:134760 .

3. Indian council of medical research evaluation of nutritional anaemia prophylaxis program task force study New Delhi; 1989. Available at; https://www.icmr.nic.in/sites/default/files/icmr_bulle tins/bufeb00.pdf. Accessed on 3 February 2021.

4. Centre for disease control (CDC), criteria for anaemia in children and child bearing age women MMWR. 1989;38:400-4; Available at https://www.cdc.gov/MMWR/preview/mmwrhtml/0 0051880.htm. Accessed on 3 February 2021. 
5. FOGSI General Clinical Practice Recommendations. Management of Iron Deficiency Anemia in Pregnancy. Available at; www.fogsi.org/ wpcontent/uploads/2017/07/gcpr-recommend ationida.pdf. Accessed on 3 February 2021.

6. Guidelines for Prevention of Maternal Anaemia. Available at; http://www.nrhmtn.gov.in/ guideline/RGPMA.pdf.

7. Lone FW, Qureshi RN, Emanuel F. Maternal anaemia and its impact on perinatal outcome. Trop Med Int Health. 2004;9(4):486-90.

8. Longo SA, Moore RC, Canzoneri BJ, Robichaux A. Gastrointestinal Conditions during Pregnancy. Clin Colon Rectal Surg. 2010;23(2):80-9

9. Milman N. "Prepartum anaemia: prevention and treatment," Annals Hemat. 2008;87(12):949-59.

10. Joshi SD, Chikkagowdra S, Kumar VCM. Comparative study of efficacy and safety of intravenous ferric carboxy maltose versus iron sucrose in treatment of postpartum iron deficiency anemia. Int J Reprod Contracept Obstet Gynecol. 2016;5.

11. Seid MH, Derman RJ, Baker JB, Banach W, Goldberg C, Rogers R. "Ferric carboxymaltose injection in the treatment of postpartum iron deficiency anemia: a randomized controlled clinical trial,". Am J Obstet and Gyneco, 2008;199(4):435-7.

12. VanWyck DB, Martens MG, Seid MH, Baker JB, Mangione A. "Intravenous ferric carboxymaltose compared with oral iron in the treatment of postpartum anemia: a randomized controlled trial," Obstet and Gynec. 2007;110(2): 267-78, part 1.

13. Breymann C, Gliga F, Bejenariu C, Strizhova N, "Comparative efficacy and safety of intravenous ferric carboxymaltose in the treatment of postpartum iron deficiency anemia," Int J Gynec and Obstet. 2008;101(1):67-73.

14. A. Pfenniger, C. Schuller, P. Christoph, and D. Surbek, "Safety and efficacy of high-dose intravenous iron carboxymaltose vs. iron sucrose for treatment of postpartum anemia," J Perin Medi. 2012;40(4):397-402.

15. Froessler B, Collingwood J, Hodyl NA, Dekker G. Intravenous ferric carboxymaltose for anaemia in pregnancy. BMC pregnancy and Childbirth. 2014;14(1):11.

16. Christoph $\mathrm{P}$, Schuller C, Studer H, Irion O, De Tejada BM, Surbek D. Intravenous iron treatment in pregnancy: comparison of high-dose ferric carboxymaltose vs. iron sucrose. J Perinat Med. 2012;40(5):469-74.
17. B. Myers, O. Myers, and J. Moore, "Comparative efficacy and safety of intravenous ferric carboxymaltose (Ferinject) and iron(III) hydroxide dextran (Cosmofer) in pregnancy," Obstetr Medici. 2012;5(3):105-7.

18. B. Froessler, G. Dekker, and G. McAuliffe, "To the rescue: the role of intravenous iron in the management of severe anaemia in the peri-partum setting," Blood Transfusion. 2015;13(1):150-2.

19. Ezzati M, Lopez AD, Rodgers AA, Murray CJ. Comparative quantification of health risks: Global and regional burden of disease attributable to selected major risk factors. Geneva: World Health Organization. 2004.

20. National Family Health Survey 2016. Available from: http://rchiips.org/NFHS/NFHS4/manual/ NFHS4\%20Biomarker\%20Field\%20M anual.pdf. Accessed on 3 February 2021.

21. IIPS National Family Health Survey 1998-99 (NFHS-2): Available from http://www.nfhsindia. org/india2.html. Accessed on 3 February 2021.

22. IIPS. National Family Health Survey 2005-06 (NFHS3): Available at: http://mohfw.nic.in/nfhs factsheet.htm. Accessed on 3 February 2021.

23. National Nutrition Monitoring Bureau (NNMB). 2002. NNMB Micronutrient survey. Hyderabad:National Institute of Nutrition.

24. Toteja GS, Singh P. Micronutrient profile of Indian population. New Delhi: Ind C Med Res. 2004.

25. Mahajan A, Bhagat BR, Gupta S, Mahajan B, Verma M. A comparative study of efficacy and safety of intravenous ferric carboxymaltose versus iron sucrose in the treatment of iron deficiency anaemia of pregnancy in a tertiary care hospital. Int J Reprod Contracept Obstet Gynecol. 2018;7(5):1938-42

26. Agrawal D. Masand DL. A study for efficacy and safety of ferric carboxymaltose versus iron sucrose in iron deficiency anemia among pregnant women in tertiary care hospital. Int J Reprod Contracept Obstet Gynecol. 2019;8(6):2280-5.

27. Jose, Mahey R, Sharma JB, Bhatla N, Saxena R, Kalaivani M., et al. Comparison of ferric Carboxymaltose and iron sucrose complex for treatment of iron deficiency anemia in pregnancyrandomised controlled trial BMC Preg and Childbirth. 2019;19:54.

Cite this article as: Jamkhandi S, Tile R. Safety and efficacy of ferric carboxymaltose in anaemic antenatal women: a prospective study. Int J Reprod Contracept Obstet Gynecol 2021;10:1837-41. 